\title{
Pengujian Aplikasi Pengenalan Tulisan Tangan Menggunakan Model Behaviour Use Case
}

\author{
Gita Fadila Fitriana \\ Institut Teknologi Telkom Purwokerto \\ Program Studi Rekayasa Perangkat Lunak Fakultas Informatika \\ e-mail: gita@ittelkom-pwt.ac.id
}

\begin{abstract}
Abstrak
Pengembangan perangkat lunak yang baik harus melalui proses pengujian tiap fase. Pengujian digunakan untuk mencari kesalahan perangkat lunak yang dikembangkan. Pengujian dilakukan berdasarkan kebutuhan pengembangan perangkat lunak. Pengujian ini bertujuan memvalidasi kondisi awal dan kondisi akhir sesuai dengan kebutuhan. Pada penelitian ini pengujian antarmuka dilakukan dengan model behaviour Unifed Modelling Language (UML) yaitu use case diagram. Berdasarkan hasil uji, terdapat 15 pengujian yang dilakukan terdapat 1 pengujian yang ditolak, sehingga nilai presentase pengujian 93\%. Pengujian dilakukan sesuai scenario use case. Hasil pengujian menunjukan bahwa aplikasi dapat berjalan sesuai scenario serta dapat mengetahui kualitas dari aplikasi pengenelan tulisan tangan.
\end{abstract}

Kata kunci-Behaviour, UML, Use case, Use case Skenario, Tulisan tangan

\begin{abstract}
Good software development must go through a testing process every phase. Testing is used to find software problems that are developed. Testing is done based on software development needs. This test validates the initial and final conditions as needed. In this study, testing with the behavior of the Unifed Modelling Language (UML) model, namely the use case diagram. Based on the test results, there were 15 tests conducted there was 1 test that was rejected, then the percentage of testing was 93\%. Testing is done according to the use case scenario. The test results show the application can run according to the scenario and can find the quality of the handwriting application.
\end{abstract}

Keywords - Behaviour, UML, Use case, Use case Scenario, Handwriting

\section{PENDAHULUAN}

Perangkat lunak yang sesuai dengan standar harus melalui proses pengembangan perangkat lunak atau yang biasa disebut Software Development Life Cycle (SDLC). Model siklus hidup pengembangan perangkat lunak (SDLC) mencakup rentang dari prediksi ke adaptif. SDLC prediktif adalah ditandai dengan pengembangan persyaratan perangkat lunak terperinci, perencanaan proyek terperinci, dan perencanaan minimal untuk iterasi di antara fase pengembangan [1]. Pengujian sistem merupakan fase yang wajib diperhatikan serta dibutuhkan untuk meningkatkan kualitas sistem yang sudah ada agar berjalan sesuai fungsinya. Setiap proses dari pengembangan perangkat lunak harus melalui tahap pengujian, sebab proses kebutuhan (requirement), analisis, perancangan dan implementasi tidak terlepas dari kesalahan [2] [2]. Adapun beberapa aturan yang digunakan untuk melakukan pengujian perangkat lunak 
yaitu pengujian dilakukan sebuah proses eksekusi program dengan tujuan utama mencari kesalahan, kemungkinan penemuan kesalahan yang tinggi dapat dikatakan baik pada sebuah kasus pengujian dan pengujian menemukan kesalahan merupakan pengujian yang berhasil [3].

Jaminan mutu dari sebuah sistem merupakan bagian penting dalam peningkatan sistem, peningkatan sistem didasarkan pada analisa kebutuhan (requirement) perangkat lunak, pengujian sistem ini tidak memiliki metode dan kiteria formal. Dikarenakan hal tersebut membuat hasil pengujian bisa menjadi tidak konsisten, maka dari itu diperlukan alat bantu untuk menguji system yang ada berdasarkan spesifikasi model behaviour UML [2]. Pengujian perangkat lunak diperlukan skenario pengujian, model behaviour Unifed Modelling Language (UML) dapat membangun skenario pengujian. Skenario pengujian terdiri atas pengujian unit, pengujian integrasi dan pengujian sistem [4]. Terdapat 14 diagram di UML digunakan untuk menjelaskan proses pengembangan perangkat lunak yang dikembangkan, ada 2 aspek yaitu aspek prilaku (behaviour aspect) yang bersifat dinamis dan aspek struktural (struktural aspek) yang bersifat statis [5]. Perubahan yang terjadi pada sistem sejalan dengan perubahan waktu dijelaskan pada aspek perilaku, berbeda pada aspek struktural yang menggambarkan struktur elemen-elemen pembentuk sistem yang tidak ada kaitannya dengan waktu, yaitu konsep lebih dari sebuah aplikasi [6].

Pengujian dengan model behaviour dengan objek aplikasi pengenalan tulisan tangan, tulisan tangan merupakan pengenalan pola karakter, dikarenakan cara penulisan tiap orang yang berbeda atau bervariasi sehingga menyebabkn bentuk tulisan tangan yang tidak konsisten seperti tulisan tangan yang mengalami rotasi dan ukuran tulisan berbeda menjadi permasalahan [7]. Aplikasi pengenalan tulisan tangan ini telah dilakukan implementasi perangkat lunak. Pengembangan perangkat lunak aplikasi ini menggunakan SDLC. Pada aplikasi pengenalan tulisan tangan terdapat dua form menu yaitu pelatihan dan pengujian. Tiap menu tersebut dilakukan pengujian dengan use case diagram.

Use case diagram merupakan diagram yang masuk ke dalam aspek prilaku. Diagram ini menceritakan hubungan antara sistem terhadap pengguna. Hal ini digunakan untuk menguji fungsionalitas dari aplikasi pengenalan tulisan tangan. Aplikasi tersebut tidak terlepas dari beberapa kesalahan pada tiap proses pengembangan perangkat lunak. Untuk mengharapkan fungsionalitas sistem berjalan dengan baik maka harus melalui proses pengujian yang bertujuann untuk mencari beberapa kesalahan yang terjadi pada aplikasi ini. Pengujian ini menggunakan model behaviour use case. Sebelum pengujian diimplementasikan, ada beberapa rencana pengujian menggunakan skenario untuk menguji bagian-bagian fungsionalitas aplikasi ini.

\section{METODE PENELITIAN}

\subsection{Pengujian}

Konstruksi melibatkan dua bentuk pengujian, yang sering dilakukan oleh pengembang perangkat lunak yang menulis kode yaitu pengujian unit dan pengujian integrasi. Tujuan dari pengujian konstruksi adalah untuk mengurangi kesenjangan antara waktu ketika kesalahan dimasukkan ke dalam kode dan waktu ketika kesalahan terdeteksi, mengurangi biaya yang dikeluarkan untuk memperbaikinya. Dalam beberapa kasus, pengujian dilakukan setelah kode ditulis. Dalam kasus lain, pengujian dapat dibuat sebelum kode ditulis. Dua standar telah diterbitkan pada topik pengujian konstruksi: Standar IEEE 829-1998, Standar IEEE untuk Dokumentasi Uji Perangkat Lunak, dan Standar IEEE 1008-1987, Standar IEEE untuk Pengujian Unit Perangkat Lunak [8]. 
Pengujian Unit adalah pengujian yang difokuskan pada unit terkecil pada program, pengujian ini berdasarkan informasi dari deksripsi perancangan detil perangkat lunak. Pengujian ini terbagi atas dua yaitu white box dan black box, pengujian white box digunakan untuk mendapatkan kesalahan pada persayaratan fungsional tanpa mengabaikan kerja bagian dalam dari suatu perangkat lunak [9]. Pengujian white box dapat digunakan juga untuk mengetahui kompleksitas pada kode program [10]. Pengujian black box merupakan pengujian yang yang memperhatikan detail sistem dari funsginya, medeteksi kesalahan pada fungsi antarmuka, kesalahan pada model data serta kesalahan pada alur data yang disimpan pada basis data [11].

Pada penelitian ini, pengujian antarmuka dilakukan dengn model behaviour yaitu use case diagram. Pengujian ini memastikan bahwa informasi masukan (input) dan keluaran (output) dari modul-modul perangkat lunak mengalir dengan benar.

\subsection{Unifed Modelling Language (UML)}

Pengujian system ini dilakukan dengan model behaviour UML, beberaapa diagram UML diantaranya use case diagram, class diagram, activity diagram, class diagram, dan sequence diagram [12]. Penelitian ini hanya menggunakan use case diagram untuk menguji antarmuka pada aplikasi pengenalan tulisan tangan.

\subsubsection{Use Case}

Use case diagram merupakan diagram yang menjelaskan secara rinci menggunakan dokumen yaitu use case skenario. Use case scenario ini mendeskripsikan secara tekstual antara aktor dengan sistem, berbeda hal dengan use case diagram yang merupakan gambaran representasi dari sistem yang dikembangkan. Use case scenario dijelaskan dalam bentuk tekstual yang bergantung pada format kebutuhannya, yaitu informal, singkat, dan lengkap. Use case scenario juga menceritakan kondisi awal dan kondisi akhir pada sistem. Pada scenario terdapat bagian-bagian penting yaitu aktor, kondisi awal, kondisi akhir, skenario utama, dan skenario alternatif [13].

Use case diagram digambarkan dalam visualisas hubungan antara aktor dengan sistem. Elemen-elemen pada use case diagram yaitu aktor, use case, asosiasi, include, extend dan hubungan generalisasi. Aktor merupakan orang atau sistem yang memperoleh manfaat dari dan bersifat eksternal terhadap subjek. Aktor dinotasikan dengan symbol gambar orang-orangan (stickman). Use case dinotasikan dengan bentuk elips dengan nama kata kerja yang aktif pada bagian dalamnya yang menceritakan aktivitas dari perspektif aktor. Setiap use case diperbolehkan berinteraksi dengan sistem dan banyak aktor dapat menjalankan satu use case. Extend merupakan hubungan tambahan ke sebuah use case, dimana use case yang ditambahkan dapat berdiri sendiri tanpa use case tambahan dan arah panah mengarah pada use case yang ditambahkan. Sedangkan include merupakan tambahan use case dimana membuthkan use case ini untuk menjalakan fungsinya atau use case ini sebagai syarat untuk menjalankan use case ini, arah panah mengarah pada use case yang dibutuhkan. Hubungan generalisasi merupakan hubungan umum ke khusus, arah panah mengarah pada use case yang menjadi umum [14].

\subsection{Metode Pengembangan Perangkat Lunak}

Metode pengembangan perangkat lunak Aplikasi Pengenalan Tulisan Tangan menggunakan SDLC, Secara umum memiliki 4 fase yaitu planning (perencanaan), analisis, desain, dan implementasi. Berikut ini penjelasan tiap fase SDLC yaitu: 
A. Planning (perencanaan

1. Pengumpulan kebutuhan

- Bahan-bahan berupa jurnal, buku serta dari internet yang berkaitan dengan penelitian ini. Kebutuhan pada perangkat lunak ini berupa dua buah data tulisan tangan angka yaitu data primer dan data sekunder.

- Implementasi aplikasi ini menggunakan Netbeans JDK 7.2.

- Microsoft Word 2010 untuk dokumentasi aplikasi pengenalan tulisan tangan.

- Perangkat keras yang digunakan pada sistem ini yaitu Prosessor Intel(R) Core (TM) i5520M CPU @ 2.40 GHz, RAM 4.00 GB, dan Hard Disk 500 GB.

B. Analisis

1. Analisis kebutuhan

Kebutuhan yang telah dikumpulkan dari user dan stakeholder kemudian di analisis untuk menentukan prioritas implementasinya.

2. Analisis perangkat lunak: perangkat lunak yang digunakan adalah bahasa pemrograman java, IDE Netbeans, serta Sistem Operasi Windows 7 (seven).

3. Analisis perangkat keras: Analisa kebutuhan perangkat keras terhadap sistem seperti kecepatan processor, kapasitas memori utama dan memori sekunder.

C. Desain

1. Rancangan Antarmuka Merancang tampilan masukan dan keluaran yang berbasis GUI menggunakan IDE Netbeans 7.2 .

2. Rancangan Objek

Merancang modul-modul program dalam bentuk objek yang digunakan pada saat pengkodean sistem. Rancangan modul dapat berbentuk algoritma, UML dan pseudo-code.

D. Implementasi

1. Construction

Bahasa pemrograman yang digunakan adalah bahasa Java sesuai sesuai dengan diagram UML untuk melihat hubungan antar kelas pada aplikasi. Rancangan UML yang telah dibuat, desain antarmuka menggunakan Microsoft Visio 2013.

2. Pengujian

- Mempersiapkan pengujian terhadap aplikasi berupa data masukan.

- Melakukan implementasi rencana pengujian terhadap aplikasi pengenalan tulisan tangan berupa masukan data selain format .BMP, input cluster, tidak input nama cluster

- Menguji peringatan pada aplikasi kondisi tidak sesuai dengan keluaran yang diharapkan.

\subsection{Rencana Pengujian}

Salah satu teknik pengujian melalui model behaviour diagram use case, ada 2 pengujian dilakukan yaitu antarmuka dan unit. Pengujian ini bertujuan untuk mengetahui banyaknya kesalahan yang terjadi pada aplikasi pengenalan tulisan tangan. Aplikasi ini terdiri atas 2 menu yaitu pelatihan dan pengujian, aplikasi ini bertujuan untuk mengenali tulisan tangan seseorang dengan mengidentifikasi dari citra tulisan tangan. Citra tulisan tangan ini kemudian dilakukan proses ekstraksi ciri dan selanjutnya dilakukan klaster berdasarkan metode Jaringan Syaraf Tiruan (JST).

Pengujian perangkat lunak ini dilakukan pada setiap proses menu pelatihan dan pengujian melalui scenario use case yang terlampir di Tabel 1, Tabel 2, Tabel 3 dan Tabel 4. Setelah skenario use case, identifikasi pengujian dilakukan agar fokus pada pengujian tiap menu yang

Fitriana, (Pengujian Aplikasi Pengenalan Tulisan Tangan Menggunakan Model Behaviour Use Case) 
telah diuraikan dari skenario use case. Proses pengujian dimulai dari mengikuti proses skenario use case dengan memberikan masukan (input) yang sesuai kemudian keluaran (output) yang diharapkan serta hasil yang diterima, apakah sesuai dengan keluaran yang diharapkan atau tidak. Jika hasil yang dikeluarkan sesuai dengan yang diharapkan maka kesimpulan diterima dan jika hasil yang dikeluarkan tidak sesuai harapan maka hasilnya ditolak. Berikut gambar antarmuka aplikasi pengenalan tulisan tangan, Gambar 1 menunjukkan halaman utama.

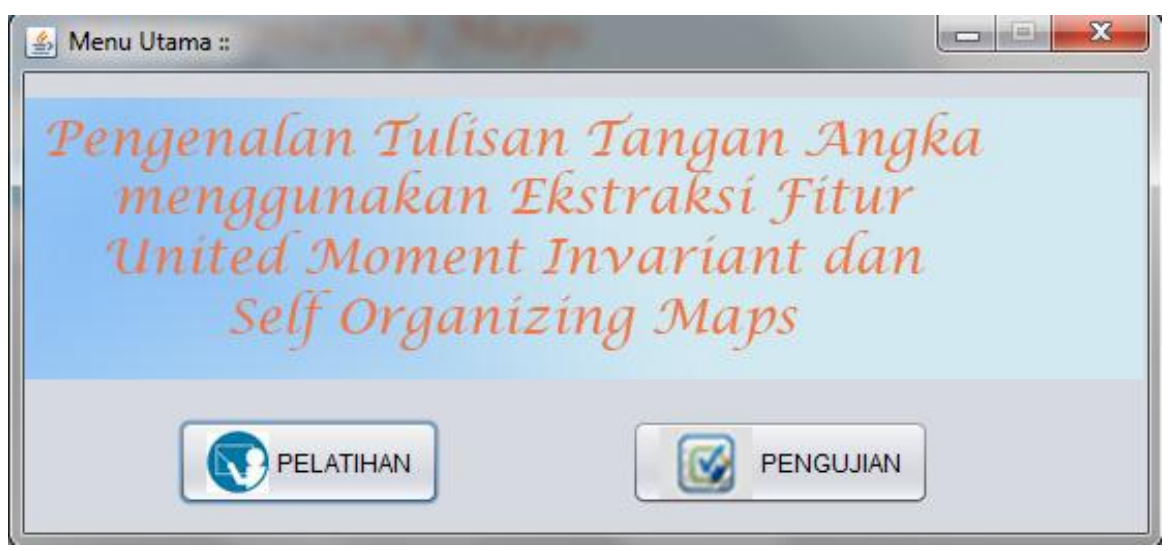

Gambar 1. Antarmuka Menu Utama

Gambar 2 menunjukkan hasil implementasi antarmuka perangkat lunak untuk menu pelatihan.

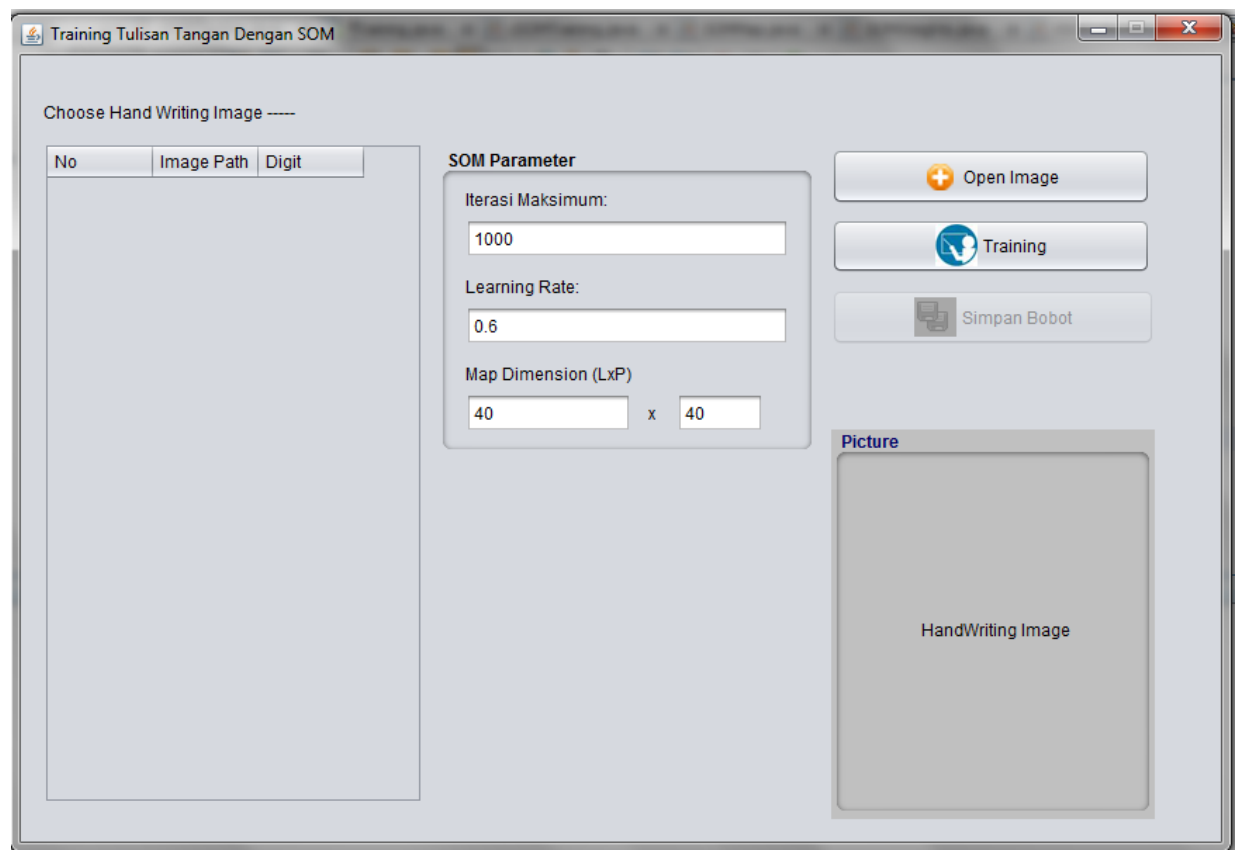

Gambar 2. Antarmuka Menu Pelatihan.

Gambar 3 menunjukkan hasil implementasi antar muka perangkat lunak untuk menu pengujian. 


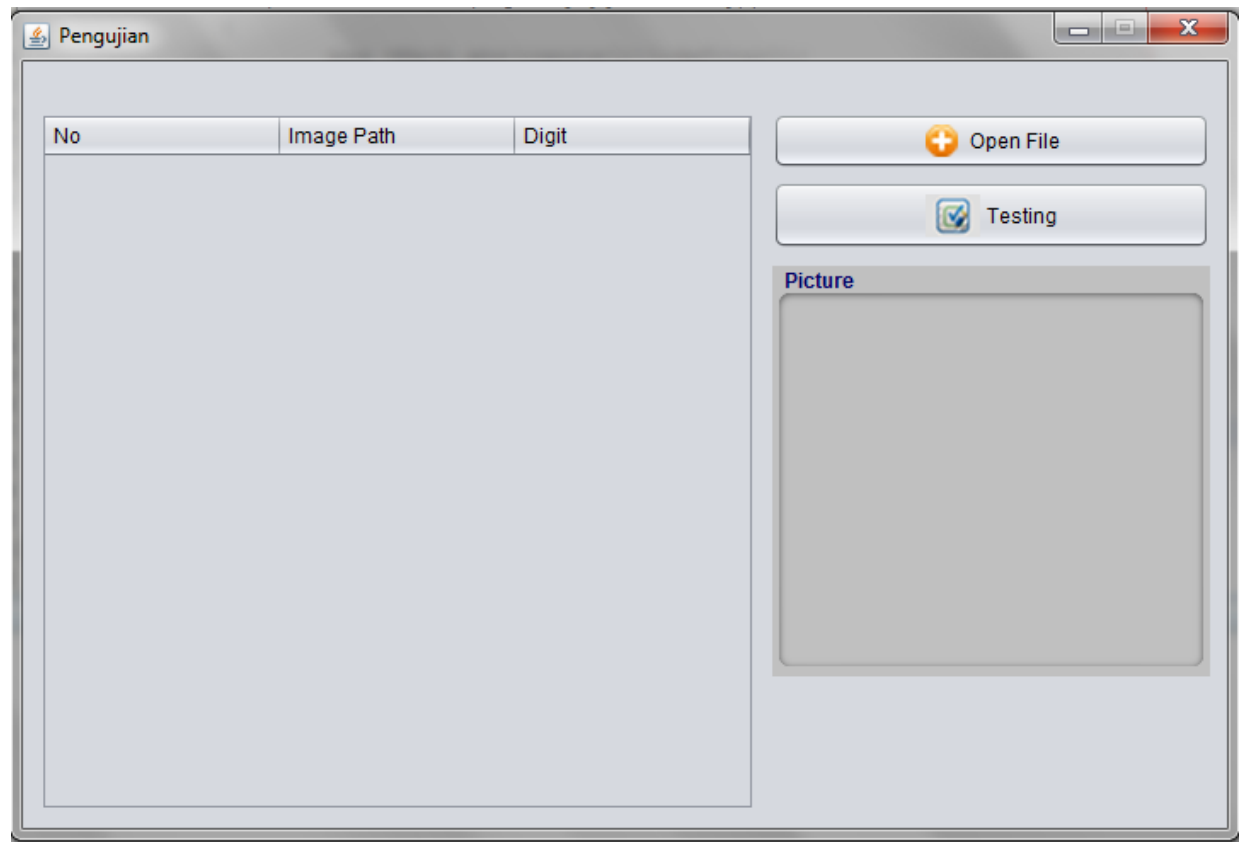

Gambar 3. Antarmuka Menu Pengujian.

\section{HASIL DAN PEMBAHASAN}

\subsection{Model Diagram Use Case}

Model diagram use case merupakan representasi dari perangkat lunak. Digaram ini digunakan untuk memberi tahu apa yang akan dilakukan system dan digunakan untuk berkomunikasi dengan pengguna. Diagram use case dapat dilihat pada Gambar 4.

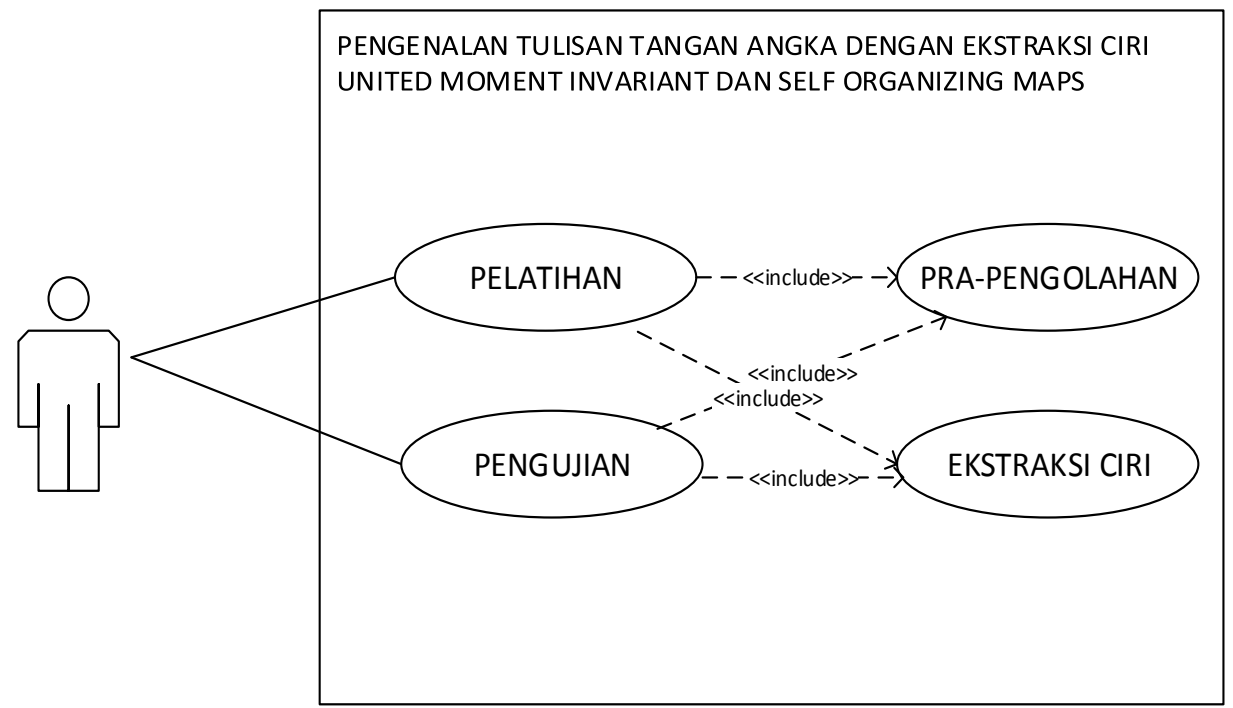

Gambar 4. Diagram Use Case 


\subsection{Skenario Use Case}

Skenario adalah urutan spesifik dari aksi dan interaksi antara aktor dan sistem. Berikut ini adalah skenario dari use case yang telah didefinisikan sebagai berikut:

1. Skenario Use case Pra-pengolahan Citra Tulisan Tangan

Pada bagian ini menjelaskan tentang skenario use case pra-pengolahan dapat dilihat pada Tabel 1.

Tabel 1. Skenario Use Case Pra-Pengolahan Citra Tulisan Tangan

\begin{tabular}{|l|l|}
\hline No. & 001 \\
\hline Nama Use case & Pra-pengolahan. \\
\hline Aktor & - \\
\hline Tujuan & $\begin{array}{l}\text { Mempersiapkan gambar yang akan dilakukan proses pembelajaran atau } \\
\text { pengenalan. }\end{array}$ \\
\hline Deskripsi & $\begin{array}{l}\text { Use case ini digunakan untuk melakukan proses binerisasi dari tulisan } \\
\text { tangan yang telah diakuisisi untuk mengurangi noise dan } \\
\text { menstandarisasi gambar. }\end{array}$ \\
\hline Kondisi Awal & Sistem telah berjalan. \\
\hline Kondisi Akhir & Citra tulisan tangan telah normal. \\
\hline Skenario Utama & Sistem \\
\hline Aktor & \begin{tabular}{l} 
1. Menemukan posisi pixel tulisan tangan \\
\hline Skenario Normal
\end{tabular} \\
\hline \multicolumn{3}{|l|}{$\begin{array}{l}\text { Melakukan operasi perubahan gambar } \\
\text { binerisasi berdasarkan data tulisan tangan } \\
\text { yang dipilih }\end{array}$} \\
\hline
\end{tabular}

2. Skenario Use case Ekstraksi Ciri Citra Tulisan Tangan

Pada bagian ini menjelaskan tentang skenario use case ekstraksi ciri dapat dilihat pada Tabel 2 .

Tabel 2. Skenario Use Case Ekstraksi Ciri Citra Tulisan Tangan

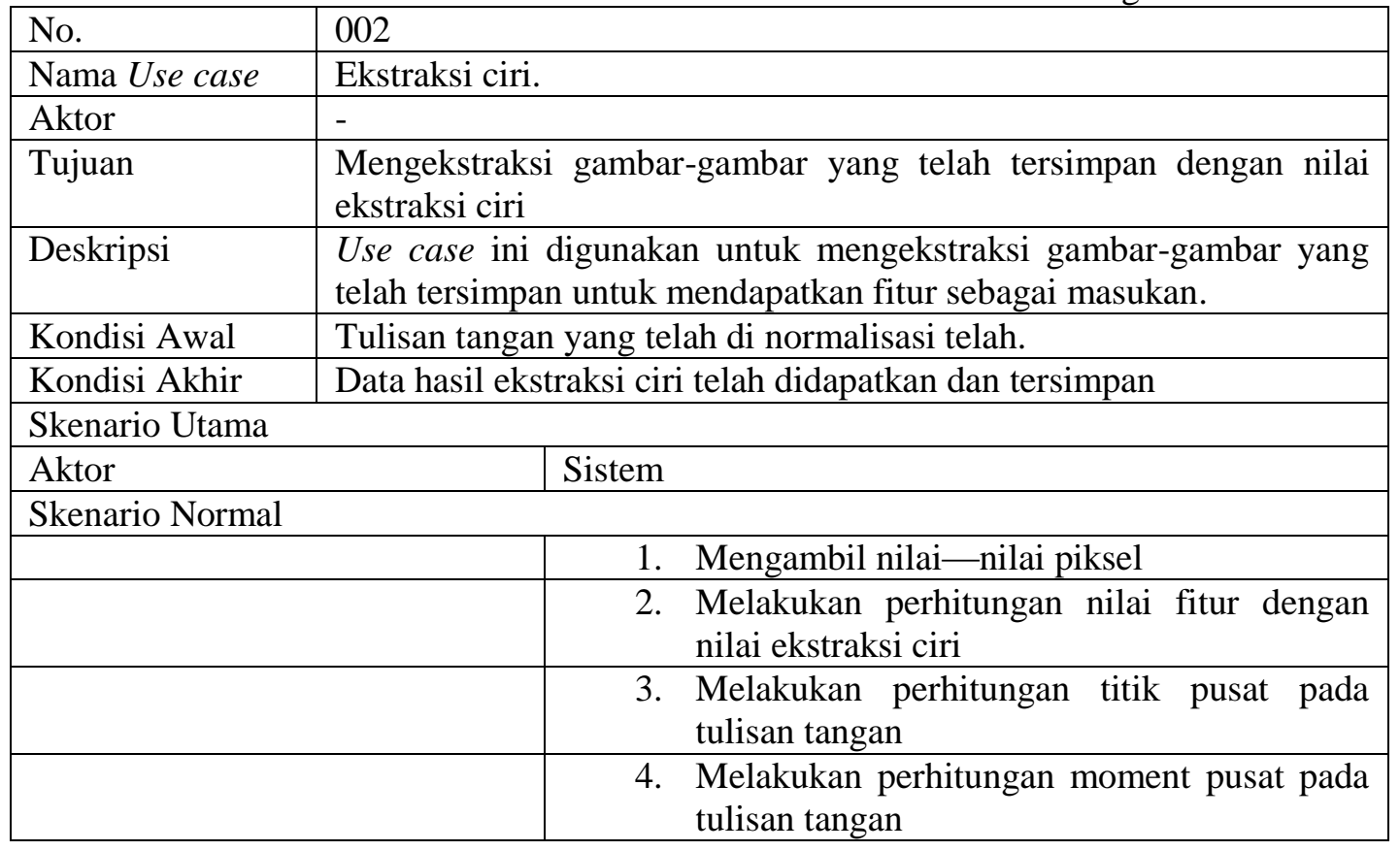




\begin{tabular}{|l|l|}
\hline & $\begin{array}{l}\text { 5. Menghitung moment pusat ternormalisasi } \\
\text { pada tulisan tangan }\end{array}$ \\
\hline 6. Menampilkan nilai fitur & \\
\hline
\end{tabular}

3. Skenario Use case Pelatihan Citra Tulisan Tangan

Pada bagian ini menjelaskan tentang skenario use case pelatihan dapat dilihat pada Tabel 3.

Tabel 3. Skenario Use Case Pelatihan Ciri Citra Tulisan Tangan

\begin{tabular}{|c|c|c|}
\hline No. & \multicolumn{2}{|l|}{003} \\
\hline Nama Use case & \multicolumn{2}{|c|}{ Melatih Citra Tulisan Tangan. } \\
\hline Aktor & \multicolumn{2}{|c|}{ Pengguna. } \\
\hline Tujuan & \multicolumn{2}{|c|}{ Mempelajari setiap tulisan tangan yang akan dikenali. } \\
\hline Deskripsi & \multicolumn{2}{|c|}{$\begin{array}{l}\text { Use case ini digunakan untuk melakukan pelatihan dengan Self } \\
\text { Organizing Maps. }\end{array}$} \\
\hline Kondisi Awal & \multicolumn{2}{|l|}{ Sistem telah berjalan. } \\
\hline Kondisi Akhir & \multicolumn{2}{|c|}{ Citra tulisan tangan telah dilatih. } \\
\hline \multicolumn{3}{|l|}{ Skenario Utama } \\
\hline \multicolumn{2}{|l|}{ Aktor } & Sistem \\
\hline \multicolumn{3}{|l|}{ Skenario Normal } \\
\hline \multirow{2}{*}{\multicolumn{2}{|c|}{$\begin{array}{l}\text { 1. Pengguna menekan tombol } \\
\text { Training }\end{array}$}} & \\
\hline & & 2. $\quad$ Menampilkan form Training \\
\hline \multirow{2}{*}{\multicolumn{2}{|c|}{$\begin{array}{l}\text { 3. Pengguna menekan tombol Open } \\
\text { Image }\end{array}$}} & \\
\hline & & 4. $\quad$ Menampilkan kotak dialog open \\
\hline \multicolumn{2}{|c|}{$\begin{array}{l}\text { 5. Pengguna memilih citra tulisan } \\
\text { tangan data primer atau data } \\
\text { sekunder }\end{array}$} & \\
\hline \multirow{2}{*}{\multicolumn{2}{|c|}{$\begin{array}{l}\text { 6. Pengguna memberi nama cluster } \\
\text { pada data yang akan di training }\end{array}$}} & \\
\hline & & $\begin{array}{ll}\text { 7. Menampilkan path dan citra tulisan } \\
\text { tangan yang akan di training }\end{array}$ \\
\hline \multirow{8}{*}{\multicolumn{2}{|c|}{$\begin{array}{l}\text { 8. Pengguna } \\
\text { Training } \\
\end{array}$}} & \\
\hline & & 9. Menginisialisasi nilai-nilai masukan \\
\hline & & $\begin{array}{l}\text { 10. } \begin{array}{l}\text { Menginisialisasi bobot-bobot dengan } \\
\text { nilai acak }\end{array} \\
\end{array}$ \\
\hline & & $\begin{array}{l}\text { 11. Menghitung keluaran nilai output dengan } \\
\text { menggunakan euclidean distance untuk } \\
\text { mencari nilai terkecil sebagai pemenang }\end{array}$ \\
\hline & & $\begin{array}{l}\text { 12. Memperbarui nilai pemenang dan nilai } \\
\text { tetangga }\end{array}$ \\
\hline & & $\begin{array}{l}\text { 13. Melakukan ulang proses penghitungan } \\
\text { euclidean distance hingga epoch tercapai }\end{array}$ \\
\hline & & $\begin{array}{l}\text { 14. Jika nilai iterasi (epoch) tercapai } \\
\text { maka proses training selesai }\end{array}$ \\
\hline & & 15. Menampilkan alert Train Finished! \\
\hline 16. Pengguna & menekan tombol & \\
\hline
\end{tabular}

Fitriana, (Pengujian Aplikasi Pengenalan Tulisan Tangan Menggunakan Model Behaviour Use Case) 


\begin{tabular}{|l|l|}
\hline simpan bobot & \\
\hline & $\begin{array}{l}\text { 17. Menampilkan alert Bobot Hasil } \\
\text { Training Disimpan! }\end{array}$ \\
\hline
\end{tabular}

4. Skenario Use case Testing Citra Tulisan Tangan

Pada bagian ini menjelaskan tentang skenario use case pengujian citra tulisan tangan dapat dilihat pada Tabel 4.

Tabel 4. Skenario Use Case Testing Citra Tulisan Tangan

\begin{tabular}{|c|c|c|}
\hline No. & \multicolumn{2}{|l|}{004} \\
\hline Nama Use case & \multicolumn{2}{|c|}{ Mengenali citra tulisan tangan. } \\
\hline Aktor & \multicolumn{2}{|l|}{ Pengguna. } \\
\hline Tujuan & \multicolumn{2}{|c|}{ Mengenali Tulisan Tangan. } \\
\hline Deskripsi & \multicolumn{2}{|c|}{$\begin{array}{l}\text { Use case ini digunakan untuk mengenali tulisan tangan angka yang } \\
\text { diuji pada sistem. }\end{array}$} \\
\hline Kondisi Awal & \multicolumn{2}{|c|}{ Citra tulisan tangan angka belum dikenali sistem. } \\
\hline Kondisi Akhir & \multicolumn{2}{|c|}{ Citra tulisan tangan angka sudah dikenali sistem. } \\
\hline \multicolumn{3}{|l|}{ Skenario Utama } \\
\hline Aktor & & Sistem \\
\hline \multicolumn{3}{|c|}{ Skenario Normal } \\
\hline \multicolumn{3}{|c|}{$\begin{array}{l}\text { 1. Pengguna menekan tombol } \\
\text { Testing }\end{array}$} \\
\hline & & 2. Menampilkan kotak dialog open \\
\hline \multicolumn{3}{|c|}{$\begin{array}{l}\text { 3. Pengguna memilih citra } \\
\text { tulisan tangan yang akan } \\
\text { ditesting }\end{array}$} \\
\hline \multicolumn{3}{|c|}{$\begin{array}{l}\text { 4. Pengguna menekan tombol } \\
\text { testing }\end{array}$} \\
\hline & & $\begin{array}{l}\text { 5. Melakukan pengenalan dan } \\
\text { menampilkan citra tulisan tangan angka } \\
\text { dikenali }\end{array}$ \\
\hline
\end{tabular}

Identifikasi pengujian pada aplikasi dari usecase diagram diuraikan pada Tabel 5, Tabel 6, Tabel 7, dan Tabel 8.

Tabel 5. Identifikasi Pengujian Use Case Pra-Pengolahan Citra Tulisan Tangan

\begin{tabular}{|c|c|l|}
\hline No. & Identifikasi & \multicolumn{1}{|c|}{ Pengujian } \\
\hline 1. & P-1-101 & Pemrosesan tanpa gambar \\
\hline 2 & P-1-102 & Pemrosesan dengan gambar \\
\hline 3. & P-1-103 & $\begin{array}{l}\text { Pemrosesan gambar dengan } \\
\text { ekstensi bukan BMP }\end{array}$ \\
\hline
\end{tabular}

Tabel 6. Identifikasi Pengujian Use Case Ekstraksi Fitur Citra Tulisan Tangan

\begin{tabular}{|c|c|l|}
\hline No. & Identifikasi & \multicolumn{1}{c|}{ Pengujian } \\
\hline 1. & P-2-101 & $\begin{array}{l}\text { Penyimpanan nilai ekstraksi } \\
\text { ciri }\end{array}$ \\
\hline 2. & P-2-102 & Alert ekstraksi fitur telah \\
\hline
\end{tabular}


Tabel 7 Identifikasi Pengujian Use Case Pelatihan Citra Tulisan Tangan

\begin{tabular}{|c|c|l|}
\hline No. & Identifikasi & \multicolumn{1}{|c|}{ Pengujian } \\
\hline 1. & P-1-101 & Tampil antamuka pelatihan \\
\hline 2. & P-1-102 & Menekan tombol Open Image dan mengisi nama cluster \\
\hline 3. & P-1-103 & $\begin{array}{l}\text { Menekan tombol training tanpa memasukan data citra tulisan } \\
\text { tangan }\end{array}$ \\
\hline 4. & P-1-104 & $\begin{array}{l}\text { Menekan tombol training dengan memasukan data citra } \\
\text { tulisan tangan }\end{array}$ \\
\hline 5. & P-1-105 & Menekan tombol Simpan Bobot \\
\hline 6. & P-1-106 & Alert tersimpan \\
\hline
\end{tabular}

Tabel 8. Identifikasi Pengujian Use Case Testing Citra Tulisan Tangan

\begin{tabular}{|c|c|l|}
\hline No. & Identifikasi & \multicolumn{1}{c|}{ Pengujian } \\
\hline 1. & P-2-101 & Tampil antar muka pengujian \\
\hline 2. & P-2-102 & Menekan tombol testing tanpa memasukan data pengujian \\
\hline 3. & P-2-103 & $\begin{array}{l}\text { Menekan tombol Open Image, memilih data citra tulisan } \\
\text { tangan yang akan dikenali }\end{array}$ \\
\hline 4. & P-2-104 & Menekan tombol Testing untuk dikenali \\
\hline
\end{tabular}

\subsection{Pengujian Sistem}

Pengujian sistem bertujuan untuk memastikan bahwa perangkat lunak yang dihasilkan sesuai dengan kebutuhan (requirement) yang sebelumnya telah ditentukan. Pengujian ini dilakukan untuk mengantisipasi masalah-masalah antarmuka dan perancangan jalur penanganan kesalahan antar sistem pada perangkat lunak. Pengujian sistem dilakukan dengan mensimulasikan data salah atau data yang berpotensi salah pada antarmuka perangkat lunak. Pengujian tiap use case ditampilkan pada Tabel 10, Tabel 11, Tabel 12, dan Tabel 13.

Tabel 10. Pengujian Use Case Pra-pengolahan Citra Tulisan Tangan

\begin{tabular}{|l|l|l|l|l|l|l|}
\hline Identifikasi & $\begin{array}{l}\text { Prosedur } \\
\text { pengujian }\end{array}$ & Masukan & $\begin{array}{c}\text { Keluaran } \\
\text { yang } \\
\text { diharapkan }\end{array}$ & $\begin{array}{l}\text { Kriteria } \\
\text { evaluasi } \\
\text { hasil }\end{array}$ & $\begin{array}{l}\text { Hasil yang } \\
\text { didapat }\end{array}$ & Kesimpulan \\
\hline P-1-101 & $\begin{array}{l}\text { Menjalankan } \\
\text { aplikasi }\end{array}$ & - & $\begin{array}{l}\text { Sistem tidak } \\
\text { dapat } \\
\text { menangani } \\
\text { proses pra } \\
\text { pengolahan }\end{array}$ & - & $\begin{array}{l}\text { Sistem tidak } \\
\text { dapat } \\
\text { menangani } \\
\text { proses pra } \\
\text { pengolahan }\end{array}$ & Diterima \\
\hline P-1-102 & $\begin{array}{l}\text { Memasukkan } \\
\text { objek } \\
\text { gambar }\end{array}$ & $\begin{array}{l}\text { Sistem dapat } \\
\text { memproses } \\
\text { pra- } \\
\text { pengolahan }\end{array}$ & - & $\begin{array}{l}\text { Sistem dapat } \\
\text { memproses } \\
\text { pra- } \\
\text { pengolahan }\end{array}$ & Diterima \\
\hline P-1-103 & $\begin{array}{l}\text { Memasukan } \\
\text { objek } \\
\text { gambar }\end{array}$ & $\begin{array}{l}\text { Angka } \\
\text { 0.png }\end{array}$ & $\begin{array}{l}\text { Menampilkan } \\
\text { di list } \\
\text { pemilihan }\end{array}$ & - & $\begin{array}{l}\text { Menampilkan } \\
\text { di list } \\
\text { pemilihan }\end{array}$ & Ditolak \\
\hline
\end{tabular}




\begin{tabular}{|l|l|l|l|l|l|l|}
\hline & $\begin{array}{l}\text { format } \\
\text { berbeda }\end{array}$ & $\begin{array}{l}\text { gambar } \\
\text { format selain } \\
\text { BMP }\end{array}$ & & $\begin{array}{l}\text { gambar } \\
\text { format selain } \\
\text { BMP }\end{array}$ & \\
\hline
\end{tabular}

Tabel 11. Pengujian Use Case Ekstraksi Fitur Citra Tulisan Tangan

\begin{tabular}{|c|c|c|c|c|c|c|}
\hline Identifikasi & $\begin{array}{l}\text { Prosedur } \\
\text { pengujian }\end{array}$ & Masukan & $\begin{array}{c}\text { Keluarkan } \\
\text { yang } \\
\text { diharapkan }\end{array}$ & $\begin{array}{c}\text { Kriteria } \\
\text { evaluasi } \\
\text { hasil }\end{array}$ & $\begin{array}{c}\text { Hasil yang } \\
\text { didapat }\end{array}$ & Kesimpulan \\
\hline P-2-101 & $\begin{array}{l}\text { Memproses } \\
\text { gambar } \\
\text { untuk di } \\
\text { ekstraksi } \\
\text { fitur }\end{array}$ & - & $\begin{array}{l}\text { Sistem } \\
\text { menampilkan } \\
\text { nilai } \\
\text { ekstraksi ciri }\end{array}$ & - & $\begin{array}{l}\text { Sistem } \\
\text { menampilkan } \\
\text { nilai } \\
\text { ekstraksi ciri }\end{array}$ & Diterima \\
\hline P-2-102 & $\begin{array}{l}\text { Memproses } \\
\text { gambar } \\
\text { untuk di } \\
\text { ekstraksi } \\
\text { fitur } \\
\text { dengan } \\
\text { menekan } \\
\text { tombol } \\
\text { Training }\end{array}$ & - & $\begin{array}{l}\text { Alert dengan } \\
\text { isi "esktraksi } \\
\text { fitur telah } \\
\text { selesai" }\end{array}$ & - & $\begin{array}{l}\text { Alert dengan } \\
\text { isi "esktraksi } \\
\text { fitur telah } \\
\text { selesai" }\end{array}$ & Diterima \\
\hline
\end{tabular}

Tabel 12. Pengujian Use Case Pelatihan Citra Tulisan Tangan

\begin{tabular}{|c|c|c|c|c|c|c|}
\hline Identifikasi & $\begin{array}{l}\text { Prosedur } \\
\text { pengujian }\end{array}$ & Masukan & $\begin{array}{l}\text { Keluaran } \\
\text { yang } \\
\text { diharapkan }\end{array}$ & $\begin{array}{l}\text { Kriteria } \\
\text { evaluasi } \\
\text { hasil }\end{array}$ & $\begin{array}{l}\text { Hasil } \\
\text { yang } \\
\text { didapat }\end{array}$ & Kesimpulan \\
\hline P-3-101 & $\begin{array}{l}\text { Memilih menu } \\
\text { Training }\end{array}$ & - & $\begin{array}{l}\text { Sistem } \\
\text { menampilkan } \\
\text { form menu } \\
\text { Training }\end{array}$ & - & $\begin{array}{l}\text { Form } \\
\text { Training }\end{array}$ & Diterima \\
\hline P-3-102 & $\begin{array}{ll}\text { - } & \text { Melakukan } \\
\text { skenario P- } \\
1-101 \\
\text { - Menekan } \\
\text { tombol } \\
\text { Open } \\
\text { Image } \\
\text { - Mengisi } \\
\text { nama } \\
\text { cluster } \\
\end{array}$ & Angka 0 & $\begin{array}{l}\text { Nama cluster } \\
\text { dan data citra } \\
\text { tulisan } \\
\text { tangan } \\
\text { masuk ke } \\
\text { dalam list }\end{array}$ & $\begin{array}{l}\text { Data yang } \\
\text { dimasukkan } \\
\text { ditambahkan } \\
\text { ke dalam list }\end{array}$ & $\begin{array}{l}\text { Nama } \\
\text { cluster } \\
\text { dan data } \\
\text { citra } \\
\text { tulisan } \\
\text { tangan } \\
\text { masuk ke } \\
\text { dalam } \\
\text { list. }\end{array}$ & Diterima \\
\hline P-4-103 & $\begin{array}{ll}\text { - } & \text { Melakukan } \\
\text { skenario P- } & 1-101 \\
\text { - } & \text { Menekan } \\
\text { tombol } \\
\text { training }\end{array}$ & - & $\begin{array}{l}\text { Alert dengan } \\
\text { isi "Belum } \\
\text { ada data atau } \\
\text { data tidak } \\
\text { cukup" }\end{array}$ & $\begin{array}{l}\text { Proses } \\
\text { pengenalan } \\
\text { tulisan tangan } \\
\text { menggunakan } \\
\text { JST tidak } \\
\text { dapat } \\
\text { dilakukan } \\
\end{array}$ & $\begin{array}{l}\text { Alert } \\
\text { dengan isi } \\
\text { "Belum } \\
\text { ada data } \\
\text { atau data } \\
\text { tidak } \\
\text { cukup" } \\
\end{array}$ & Diterima \\
\hline P-5-104 & - Melakukan & Angka 0 & Alert dengan & Data yang & Alert & Diterima \\
\hline
\end{tabular}




\begin{tabular}{|c|c|c|c|c|c|}
\hline & $\begin{array}{ll} & \text { skenario P- } \\
& 1-101 \\
\text { - } & \text { Melakukan } \\
\text { skenario P- } & 1-102 \\
\text { - } & \text { Menekan } \\
& \text { tombol } \\
& \text { training }\end{array}$ & $\begin{array}{l}\text { isi "Train } \\
\text { Finished" }\end{array}$ & $\begin{array}{l}\text { dimasukkan } \\
\text { telah dilatih }\end{array}$ & $\begin{array}{l}\text { dengan isi } \\
\text { "Train } \\
\text { Finished" }\end{array}$ & \\
\hline P-6-105 & $\begin{array}{ll}\text { - } & \text { Melakukan } \\
\text { skenario P- } \\
1-101 \\
\text { - } \\
\text { Melakukan } \\
\text { skenario P- } \\
1-102 \\
\text { - } \text { Menekan } \\
\text { tombol } \\
\text { Simpan } \\
\text { Bobot } \\
\end{array}$ & $\begin{array}{l}\text { Alert dengan } \\
\text { isi "Bobot } \\
\text { hasil training } \\
\text { berhasil } \\
\text { disimpan" }\end{array}$ & $\begin{array}{l}\text { Data yang } \\
\text { dimasukkan } \\
\text { telah } \\
\text { disimpan }\end{array}$ & $\begin{array}{l}\text { Alert } \\
\text { dengan isi } \\
\text { "Bobot } \\
\text { hasil } \\
\text { training } \\
\text { berhasil } \\
\text { disimpan" }\end{array}$ & Diterima \\
\hline P-7-106 & $\begin{array}{ll}\text { - } & \text { Melakukan } \\
\text { skenario P- } & 1-101 \\
\text { - } & \text { Melakukan } \\
\text { scenario P- } & 1-102 \\
\text { - } & \text { Melakukan } \\
& \text { scenario P- } \\
& 1-103 \\
\text { - } & \text { Menekan } \\
\text { tombol OK }\end{array}$ & $\begin{array}{l}\text { Alert } \\
\text { Tertutup }\end{array}$ & - & $\begin{array}{l}\text { Alert } \\
\text { Tertutup }\end{array}$ & Diterima \\
\hline
\end{tabular}

Tabel 13. Pengujian Use Case Testing Citra Tulisan Tangan

\begin{tabular}{|c|c|c|c|c|c|c|}
\hline $\begin{array}{c}\text { Identifi } \\
\text { kasi }\end{array}$ & $\begin{array}{l}\text { Prosedur } \\
\text { pengujian }\end{array}$ & Masukan & $\begin{array}{c}\text { Keluaran } \\
\text { yang } \\
\text { diharapkan }\end{array}$ & $\begin{array}{c}\text { Kriteria } \\
\text { evaluasi } \\
\text { hasil }\end{array}$ & $\begin{array}{c}\text { Hasil yang } \\
\text { didapat }\end{array}$ & Kesimpulan \\
\hline P-4-101 & $\begin{array}{l}\text { Memilih } \\
\text { menu } \\
\text { Testing }\end{array}$ & & $\begin{array}{l}\text { Sistem } \\
\text { menampilkan } \\
\text { form menu } \\
\text { Testing }\end{array}$ & & $\begin{array}{l}\text { Form } \\
\text { Testing }\end{array}$ & Diterima \\
\hline P-4-102 & $\begin{array}{ll}\text { - } & \text { Melakuk } \\
\text { an } \\
\text { Melakuk } \\
\text { an } \\
\text { skenario } \\
\text { P-1-101 } \\
\text { - Meneka } \\
\text { n tombol } \\
\text { Testing }\end{array}$ & - & $\begin{array}{l}\text { Sistem } \\
\text { menampilkan } \\
\text { alert berisi" } \\
\text { Tidak ada } \\
\text { yang dapat } \\
\text { diproses" }\end{array}$ & $\begin{array}{l}\text { Proses } \\
\text { pengenalan } \\
\text { tulisan } \\
\text { tangan } \\
\text { menggunak } \\
\text { an JST tidak } \\
\text { dapat } \\
\text { dilakukan }\end{array}$ & $\begin{array}{l}\text { Sistem } \\
\text { menampilk } \\
\text { an alert } \\
\text { berisi” } \\
\text { Tidak ada } \\
\text { yang dapat } \\
\text { diproses" }\end{array}$ & Diterima \\
\hline
\end{tabular}




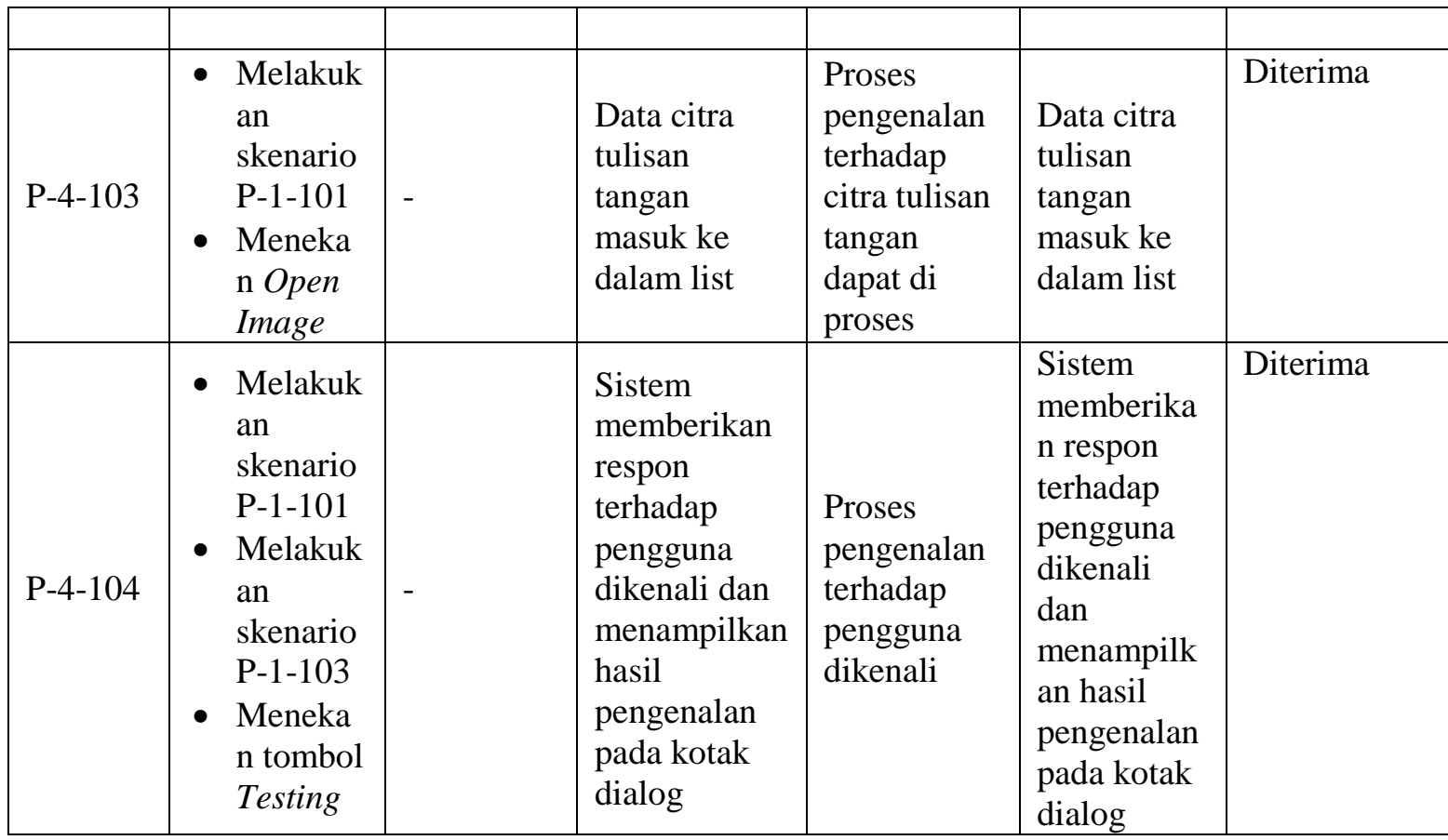

\section{KESIMPULAN}

Pengujian ini menggunakan diagram use case dari sisi fungsionalitas perangkat lunak. Berdasarkan pengujian system dibagi atas 4 pengujian sesuai dengan diagram use case. Masingmasing pengujian memiliki jumlah pengujian sesuai dengan fungsionalitas dari perangkat lunak. Dari 15 pengujian terdapat 14 pengujian yang berhasil, 1 pengujian yang ditolak. Berdasarkan pengujian dengan persentase $93 \%$. P-1-103 mengalami penolakan karena yang masukan (input) berupa PNG tidak dapat dideteksi sehingga akan dilakukan perbaikan agar gambar yang berekstensi selain BMP dapat diterima.

\section{SARAN}

Penelitian selanjutnya dapat menerapkan pengujian model behaviour UML selain use case, yaitu model sequence diagram, model activity diagram dapat dilakukan untuk melanjutkan pengujian pada form menu lainnya.

\section{DAFTAR PUSTAKA}

[1] "Project Management Institute and IEEE Computer Society, Software Extension to the PMBOK® Guide Fifth Edition, Project Management Institute, 2013."

[2] F. B. Waskitho Wibisono, "Pengujian Perangkat Lunak Dengan Menggunakan Model Behaviour UML,” JUTI, Vol. 1, No. JULI 2002, pp. 43-50, 2002.

[3] G. J. Myers, The Art of Software Testing, Second Edition. 2004. 
[4] D. Budgen, Software Design, 2nd ed., Addison-Wesle. 2003.

[5] OMG, OMG, 2017. OMG Unified Modeling Language (OMG UML) Ver. 2.5.1. Object Management Group. 2017.

[6] T. A. Kurniawan, "Pemodelan Use Case (Uml): Evaluasi Terhadap Beberapa Kesalahan Dalam Praktik," J. Teknol. Inf. dan Ilmu Komput., Vol. 5 No 1, pp. 77-86, 2018.

[7] G. F. Fitriana, "Handwriting Digit Recognition Using United Moment Invariant Feature Extraction and Self Organizing Maps," in 2014 Third ICT International Student Project Conference (ICT-ISPC), 2014.

[8] Pierre Bourque and R. E. F. (Dick), SWEBOK V3.0. 2004.

[9] A. H, "Sistem Penunjang Keputusan Pemilihan Guru Terbaik dengan Metode TOPSIS (Technique for Order Preference by Similarity to Ideal Solution) Studi Kasus: SDN Bendungan Hilir 01 Pagi Jakarta Pusat.," J. Inform. Univ. Pamulang, pp. 89-96, 2017.

[10] D. Fakhri, M. A., Aknuranda, I., \& Pramono, "Implementasi Sistem Informasi Showroom Mobil (SISMOB) dengan Pemrograman Berbasis Objek (Studi Kasus: UD. Tomaru Oto).," J. Pengemb. Teknol. Inf. dan Ilmu Komputer, pp. 2967-2974, 2018.

[11] M. Sukamto, R. A., Shalahuddin, Rekayasa Perangkat Lunak Terstruktur dan Berorientasi Objek. Bandung: Informatika. 2013.

[12] R. A. Sukamto and M. Shalahuddin, Kolaborasi Rekayasa Perangkat Lunak Terstruktur dan Berorientasi Objek. Bandung: Informatika,. 2015.

[13] L. C, LARMAN, C., 2005. Applying UML and Patterns. 3rd Edition. NJ: Prentice Hall. 2005.

[14] S.J. Mellor and M.J. Balcer, Executable UML: A Foundation for Model-Driven Architecture, 1st ed., Addison-Wesley. 2002. 